\title{
The Potential of Public Policy on Open Access Repositories
}

\author{
Nikos Koutras*
}

\begin{abstract}
To address the potential of public policy on the governance of OARs it is necessary to define what is meant by public policy and the importance of public policy in designing an efficient governance framework. Critical components are the subject matter of public policy and its objectives. Hence, it is useful to consider declarations, policies and statements in relation to open access practice and examine the efficiency of these arrangements towards the improvement of stakeholders' engagement in governance of OARs. Secondly, policies relating to dissemination of scientific information via OARs should be examined. In this regard, it is relevant to consider the public policy basis for Intellectual Property (IP) laws that concerning the utility of OARs. Therefore, economic theories relevant with the role of IP laws should be examined. Such examination depicts to what extend these laws facilitate the utility of OARs. In order to specify justifications for the desirability of OARs the objectives of social theories should be also considered. Thus, there is consternation that without legal protection against copying the incentive to create intellectual property will be undermined. As scholarly communication infrastructure evolves, it is necessary to recognize the efforts of the relationship between Intellectual Property Rights (IPRs) and communication technologies in the context of public policy and after engagement with it. After employing such multilevel approach, the paper argues about a socio-economic framework to enhance the governance of OARs through public policy.
\end{abstract}

Keywords: public policy, dissemination, governance, open access, repositories

\section{Literature Review}

In modern times, the growth of information technologies (IT) is ongoing, and digitisation of creative content is part of institutional norms. Hence, access to scientific information is of paramount importance. The literature shows that there are different options to disseminate scientific information (i.e. gold open access and green open access). The creation of Open Access Repositories (OARs) facilitates the dissemination of information. The OARs tool is one of the core elements of green open access. Scholars argue that an OAR is an online

* Nikos Koutras, Postdoctoral Researcher, Faculty of Law, University of Antwerp. database that makes the full text of items it contains freely and immediately available. ${ }^{1}$ According to the OpenAIRE project, an OAR is a database or a virtual archive established to collect, disseminate and preserve scientific output; OARs make scientific articles and datasets freely available. ${ }^{2}$ It is also argued that an OAR is a digital archive created and maintained to provide universal and free access to information in an electronic format as a means of facilitating research and scholarship. ${ }^{3}$ OARs can be linked either to an institution or to a research field or subject. ${ }^{4}$

To set up an institutional OAR, an enhancement of the associated governance infrastructure and actors involved is also required. ${ }^{5}$ Thus, the governance framework to be adopted is a subject of intense debate. ${ }^{6}$ Furthermore, the example of open government illustrates the importance of citizens' right to access documentation of the government. In turn, such access allows for public oversight. In this regard, public policy could contribute to the green open access (i.e. OARs) governance infrastructure. To address the public policy potential on governance using OARs, it is necessary to consider a variety of specific issues. First, it is necessary to define what is meant by public policy, its interaction with social laws and the importance of public policy in designing an efficient governance framework. Critical components that should be addressed are the subject matter of public policy and its objectives. ${ }^{7}$ In this

1. Stephen Pinfield, 'A Mandate to Self Archive? The Role of Open Access Institutional Repositories' (2005) 18(1) Serials: The Journal for the Serials Community 30 ('A Mandate to Self Archive?'); Peter Suber, Open Access (The MIT Press, 2012).

2. Paolo Manghi et al., 'An Infrastructure for Managing EC Funded Research Output - The OpenAIRE Project' (2010) 6(1) The Grey Journal (TGJ): An International Journal on Grey Literature <https:// pub.uni-bielefeld.de/record/1972842>.

3. Joan M. Reitz, Dictionary for Library and Information Science (Libraries Unlimited, 2004).

4. Clifford A Lynch, 'Institutional Repositories: Essential Infrastructure For Scholarship In The Digital Age' (2003) 3(2) Portal: Libraries and the Academy 327 ('Institutional Repositories').

5. Gerard Van Westrienen and Clifford A. Lynch, 'Academic Institutional Repositories: Deployment Status in 13 Nations as of Mid 2005' (2005) 11(09) D-Lib Magazine <http://www.dlib.org/dlib/september05/ westrienen/09westrienen.html?

utm_source=dbpia\&utm_medium=article_detail\&utm_campaign=refere nce> ('Academic Institutional Repositories').

6. Carlos Juiz, Carlos Guerrero and Isaac Lera, 'Implementing Good Governance Principles for the Public Sector in Information Technology Governance Frameworks' (2014) 03(01) Open Journal of Accounting 9.

7. Christoph Knill and Jale Tosun, Public Policy: A New Introduction (Palgrave Macmillan, 2012) ('Public Policy'); Charles F. Manski, 'Response to the Review of "Public Policy in an Uncertain World"' (2013) 
regard, it is useful to consider the existing declarations, policies and statements in relation to open access practice and examine the efficiency of these arrangements for the improvement of stakeholders' engagement in the governance of OARs. Open access removes price barriers (e.g. subscriptions, licensing fees, and pay-per-view fees) and permission barriers (e.g. copyright and licensing restrictions) and is aligned with the copyright holder's concession; its evaluation is of paramount importance concerning stakeholders' engagement in the governance of OARs.

Second, policies relating to the dissemination of scientific information via OARs should be examined. In this regard, it is relevant to consider the public policy basis for Intellectual Property (IP) laws concerning the utility of OARs. Therefore, economic theories relevant to the role of IP laws should be examined. This is necessary in order to ascertain the extent to which these laws facilitate the utility of OARs. In order to specify justifications for the desirability of OARs, the objectives of social theories should also be considered. It is an undeniable fact that IP is usually able to be copied by persons that have not borne any of the cost of this creativity type. Thus, there is concern that without legal protection against copying, the incentive to create IP will be undermined.

Third, as scholarly communication infrastructure evolves, it is necessary to recognise the efforts of the relationship between Intellectual Property Rights (IPRs) and communication technologies in the context of public policy and after engagement with it. Such discussion shows the relationship between IPRs and communication technologies to the influence on the public policy. After employing such a multilevel approach, the article argues about the potential of public policy on the governance of OARs.

\subsection{Participatory Democracy and Public Policy: Conceptual Foundations}

This section argues in favour of fairer regulations that could stem from public policy. In this context, it is necessary for citizens to be informed in order to be able to participate in the formulation of appropriate public policy. ${ }^{8}$ Thus, participatory democracy could be considered a significant innovation in democracy. 9 Moreover, public policy - in both aspects of its processes and substantive content - requires that people have a voice in its formation. ${ }^{10}$ In the context of the argument of the article, an obvious aspect of public policy is that access to information is critical to enabling citizens to exercise their voice, to effectively monitor government and hold government accountable and to enter into an informed dialogue about decisions that affect their lives. More-

123(570) The Economic Journal F412; Xun Wu et al, The Public Policy Primer: Managing the Policy Process (Routledge, 2010) ('The Public Policy Primer')

8. Brian Baird, 'To Improve Public Policy' (2013) 340(6131) Science 432.

9. Hercules Bantas, Jurgen Habermas and Deliberative Democracy (Smashwords, 2010).

10. Frank Fischer and Herbert Gottweis, The Argumentative Turn Revisited: Public Policy as Communicative Practice (Duke University Press, 2012) ('The Argumentative Turn Revisited'). over, citizens can improve their living standards and better their lives when they have access to knowledge. ${ }^{11}$ In the following discussion, a brief explanation of the different types of understanding of public policy sets the context for the argument that participatory democracy is a suitable device for citizens to engage in the processes of forming policies. There are several definitions of public policy, and they highlight relevant theoretical debates. The concept of social justice in the broader sense is about the links between citizens, institutions and governments. Strong public policy should solve problems efficiently, serve justice, support governmental institutions and governmental policies and encourage active citizenship. ${ }^{12}$ Thus, the ideal objective of public policy is of direct relevance to social infrastructure and consequently active citizenship. ${ }^{13}$ Public policy and governance are thus interrelated, as both require fairness, and that means adhering to principles of social justice.

Scholars argue that the challenge for governments is to find ways to engage others in the policymaking process and to make citizens' participation fundamental. ${ }^{14}$ It is imperative to realise that the term of public value stems from government actions and is an effort to benchmark the total benefits. Nevertheless, it also reflects the public's perception of fairness and distributional equity, implications of service provision for trust and legitimacy and the benefits arising from co-production of services. ${ }^{15}$ The issue of citizens' participation is part of a large debate among scholars. Such participation provides an opportunity to influence public decisions and has long been a component of the democratic decisionmaking process. ${ }^{16}$ Public administration is progressively concerned with placing the citizen at the core of policymakers' decisions. ${ }^{17}$ Not only is citizens' participation

11. Richard Calland and Kristina A Bentley, The Impact and Effectiveness of Transparency and Accountability Initiatives: Freedom of Information (SSRN Scholarly Paper No ID 2305479, Social Science Research Network, 1 July 2013) http://papers.ssrn.com/abstract=2305479 ('The Impact and Effectiveness of Transparency and Accountability Initiatives').

12. Michael Hill and Frederic Varone, The Public Policy Process (Routledge, 2014).

13. Avi Brisman, 'The Violence of Silence: Some Reflections on Access to Information, Public Participation in Decision-Making, and Access to Justice in Matters Concerning the Environment' (2013) 59(3) Crime, Law and Social Change 291 ('The Violence of Silence').

14. Ann Capling, Patrick Low and World Trade Organization, Governments, Non-State Actors and Trade Policy-Making: Negotiating Preferentially Or Multilaterally? (Cambridge University Press, 2010) ('Governments, Non-State Actors and Trade Policy-Making'); Christopher D. Piros and Jerald E Pinto, Economics for Investment Decision Makers: Micro, Macro, and International Economics (John Wiley \& Sons, 2013) ('Economics for Investment Decision Makers').

15. Jan Donovan, 'Engaging Stakeholders and Citizens in Developing Public Policy' (2003) 3.

16. Denis Bouyssou et al., Decision Making Process: Concepts and Methods (John Wiley \& Sons, 2013) ('Decision Making Process').

17. There are differing views about how public policy is formed. For further discussion about this, see Dunn (2003). For example, there are advocates who claim that public policy can be made by leaders of religious and cultural institutions for the benefit of the congregation and participants. Also see Hesmondalgh (2005) and Kahan and Braman (2005). Hesmondalgh argues that policymakers should be guided by core principles such as transparency, accessibility and openness concerning 
crucial to the scope of public policy and long-term efforts, but it can also be an additional instrument for efficient governance. ${ }^{18}$

There is extensive literature on participatory democracy, and not every scholar has the same understanding of the concept. For instance, Brown argues that participatory democracy is direct democracy in the sense that all citizens are actively involved in all important decisions. ${ }^{19}$ The concept commonly refers to movements, such as the civil rights movement or the women's suffrage movement, which gather a group of people who make decisions democratically about the direction of the group. ${ }^{20}$ Generally, it is a concept that points to political consideration regarding improving collective decisionmaking. ${ }^{21}$ It emphasises the right of everyone to participate and considers it important that everybody subjected to a collective decision has the opportunity to participate in consequential deliberation about that decision. ${ }^{22}$ Pateman argues that participatory democracy is often treated as a normative argument concerned with aspirations. This statement helps me to argue that participatory democracy establishes an ideal and that so do OARs, but both are desirable aspirations. The goal of this thesis is to build or construct an argument that justifies OARs as the foundation for creating a participatory democracy of well-informed citizens. Citizens can influence public policy by being involved in the processes of policy formation. This leads us to the next relevant issue: how to create social consensus within participatory democracy. For this reason, the next part of the argument will develop rationales for engaging people in creating fairer regulations; by implication, and more specifically, this would help in the creation of regulations regarding OARs.

\subsection{The Importance of Public Policy as a Basis for Governance}

The first issue that is relevant to the focal research question is the importance of public policy as a basis for governance. In order to address this issue, it is necessary to consider the role of public policy in guiding legislative formulation and its value in issues relevant to the governance of OARs. The literature shows that governance has been aptly considered as an instrument for

bureaucratic and decision processes. Moreover, he states, politicians and public servants are accountable to the public, and this principle illustrates the importance of public policy towards desired solutions for social concerns. It follows that policymakers should support freely accessed information sources through proper public policy. Therefore, public policy and its formulation ought to stem from the public will or the public interest.

18. M Fagence, Citizen Participation in Planning (Elsevier, 2014).

19. Wendy Brown, 'Power after Foucault' in The Oxford Handbook of Political Theory (Oxford University Press, 2006) 65.

20. Ian Brown and Christopher T Marsden, Regulating Code: Good Governance and Better Regulation in the Information Age (The MIT Press, 2013) ('Regulating Code').

21. Samantha Besson and José Luis Martí, Deliberative Democracy and Its Discontents (Ashgate Publishing, Ltd., 2006).

22. Cristina Lafont, 'Deliberation, Participation, and Democratic Legitimacy: Should Deliberative Mini-Publics Shape Public Policy?' (2015) 23(1) Journal of Political Philosophy 40 ('Deliberation, Participation, and Democratic Legitimacy'). problem-solving. ${ }^{23}$ As far as the public sector is concerned, this takes place within a context that is governed by policy, legislation, organisational design, organisational culture and in which the external environment is shaped by economic, social, political and cultural considerations. Correspondingly, relevant legislation that stems from this governance framework and protects IPRs is of paramount significance and should therefore be examined.

According to Lehman and Phelps, public policy is a principle that no person or government official can legally perform an act that tends to injure the public. ${ }^{24}$ Furthermore, public policy manifests the common sense and common conscience of the citizens that extends throughout the state and is applied to matters of public health, safety and welfare. Another crucial perspective of public policy is Kilpatrick's work that views public policy as a system of law, regulatory measures, courses of action and funding priorities concerning a given topic promulgated by a government entity of its representatives. Thus, it is realised that public policy gathers imperative content, which is inevitably linked with the law. He argues, moreover, that individuals and groups often attempt to shape public policy through education advocacy or by mobilising interest groups. Therefore, it is logical to assume that the process always follows inherent actions that stem from competing interest groups to influence policy designators in their favour. All in all, he concludes that a major aspect of public policy is law.

Geurts characterises public policy as a complex, dynamic, constantly evolving, interactive and adaptive system. Its 'making' process is stakeholder-driven. Actors are engaged in a goal-driven decision-making process and have a great deal of autonomy in the way they organise their work. The process has two dimensions: a political dimension and a production dimension. ${ }^{25}$ Thus, it is clear that the subject matter of public policy is of paramount importance from the economic, political and legal perspectives. Hence, public policy can be seen as an attempt by government to address a public issue by instituting laws, regulations, decisions or actions that are pertinent to the problem at hand and that harmonise with concerns that stem from the rapid growth of technology infrastructure. ${ }^{26}$

Further, Habermas has developed the concept of 'public sphere'27 in order to delineate the proper operation of

23. Christopher Ansell and Jacob Torfing, Handbook on Theories of Governance (Edward Elgar Publishing, 2017).

24. Jeffrey Lehman and Shirelle Phelps, West's Encyclopedia of American Law (Thomson/Gale, 2005).

25. Thei Geurts, 'Public Policy Making: The 21st Century Perspective', Be Informed - The Business Process Platform (18 July 2011) http:// beinformedblog.blogspot.com.au/2011/07/public-policy-making-21stcentury.html ('Be Informed - The Business Process Platform').

26. For further information regarding public policy, see Smith and Larimer (2013), Theodoulou and Cahn (2012) and Birkland (2010).

27. Jürgen Habermas is a German sociologist and philosopher in the tradition of critical theory and pragmatism. He was one of the second generation of philosophers and social theorists in the Frankfurt School whose members included Horkheimer, Adorno, Walter Benjamin, Erich Fromm and Herbert Marcuse. Moreover, global polls consistently find that Hab- 
the public sphere. ${ }^{28}$ On the basis of Habermas' work, the simplicity of the public sphere forms a reality in which different considerations, specifically to address societal needs, are clearly and freely traded, unrestrained by exterior compulsions. Hence, Habermas' 'public sphere' offers an appropriate framework for an effective public policy basis in relation to OARs governance. However, in order to examine public policy as basis and benchmark, it is imperative to adopt Habermas' preceding notion of 'public sphere' and its content. Further, it can be utilised to address the question of how public policy supports as an additional instrument for open access infrastructure and freedom of information. According to Habermas, it is an area in social life where individuals can come together to freely discuss and identify daily problems of society, and within this discourse, political action is influenced. Moreover, Habermas' use of the term 'public sphere' signifies a realm of social life in which something approaching public opinion can be formed. Furthermore, it is admitted that access is guaranteed to all citizens. As a result, citizens act as a public body when they confer in an unrestricted fashion concerning general interest matters. Therefore, in a large public body, this kind of communication requires specific instruments for transmitting information and influencing those who receive it.

In addition, the public sphere is an incoherent space where individuals and groups of interest assemble to argue about issues of common interest and, where feasible, reach a mutual judgement. Accordingly, the public sphere can be seen as a theatre in contemporary societies where political participation is enacted through the medium of discussion and as a realm of social life where public opinion can be formed. Moreover, Habermas argues that the public sphere was coextensive with public authority. For that reason, it can be stated that the characteristics of public policy, from Aristotlian perspective and as inherent idioms, is public authority. ${ }^{29}$ Furthermore, this type of authority can have a parallel meaning to public policy; hence, it is recognised that its norms and forms are of paramount importance in relation to public interest and information access within the public domain.

The significant discourse in relation to the ideal belief in Habermas' 'public sphere' is that the government's laws, policies and regulations should be steered by the 'public sphere', and the only legitimate governments are those that comprehend the importance of the 'public sphere'. Thus, public policy stems from this discussion, and individual needs are a basic part of its subject mat-

ermas is widely acknowledged as one of the world's leading intellectuals. To sum up, his significant (and continuing) contributions in the late twentieth and early twenty-first centuries to philosophy, political theory, communication theory, critical social theory, legal theory, critical education studies, among other disciplines, are renowned.

28. Jürgen Habermas, The Theory of Communicative Action: Reason and the Rationalization of Society, Volume 1: Reason and the Rationalization of Society Vol 1 (Polity, 1 edition, 2015) ('The Theory of Communicative Action').

29. Aristotle, The Nicomachean Ethics, ed Lesley Brown, tr David Ross (Oxford University Press, Revised edition, 2009). ter. Taking everything into account, an efficient governance framework for OARs ought to have an inevitable link with public opinion, public interest and mutual judgement.

Considerable debate prevails over whether there is one coherent set of principles that can govern the study and understanding of the public policy process. ${ }^{30}$ As in every field of endeavour, the definition of key terms and ideas is often very important, but it can also lead to considerable contention. The proper author of public policy is a subject of continuing debate. It has been suggested that public policies can be made by leaders of religious and cultural institutions for the benefit of the congregation and participants. Literature reflects that there are many possible ways to define public policy. ${ }^{31}$ Scholars argue that public policy is whatever governments decide to do or not to do. ${ }^{32}$ According to Peters, public policy defines the sum of government activities, whether acting directly or through agents, as it has an influence on the life of citizens. ${ }^{33}$ Other scholars state that public policy consists of political decisions for the implementation of programmes to achieve societal objectives. ${ }^{34}$

Reaching a consensus on one definition regarding the public policy seems to be problematic since all of the variants of the definition suggest that public policymaking is public - it affects a greater variety of people and interests than do private decisions. ${ }^{35}$ Therefore, government and the policies made by government are sometimes very controversial and frustrating, yet very important. But because the public is the source of political authority - that is, the authority to act on the public's behalf - it is clear that government is at the centre of efforts to make public policy.

As a result, this issue should be examined in relation to open access, its influences and its significant link to technological developments. A contrary view is that public policy and its formulation ought to stem from the public will or the public interest. Piros and Pinto, for example, note that the challenge for governments is to find a way to engage others in the policymaking process. ${ }^{36}$ However, it should not be forgotten that citizens' participation is fundamental. It is acknowledged that the infrastructure of public administration is progressively

30. E. Sørensen and J. Torfing, Theories of Democratic Network Governance (Springer, 2016)

31. Lafont (n. 22).

32. Thomas R. Dye, Understanding Public Policy (Prentice Hall, 1995).

33. B Guy Peters, 'Governance as Political Theory' in Civil Society and Governance in China (Palgrave Macmillan, New York, 2012) 17 https://link.springer.com/chapter/10.1057/9781137092496_2.

34. Charles L. Cochran and Eloise F. Malone, Public Policy: Perspectives and Choices (Lynne Rienner Publishers, 2014) ('Public Policy').

35. Beatrice Crona and John Parker, 'Learning in Support of Governance: Theories, Methods, and a Framework to Assess How Bridging Organizations Contribute to Adaptive Resource Governance' (2012) 17(1) Ecology and Society https://www.ecologyandsociety.org/vol17/iss1/ art32/ ('Learning in Support of Governance').

36. It is imperative to realise that the term of public value stems from government actions and is an effort that concerns benchmarking the total benefits flowed. Nevertheless, it also reflects the public's perception of fairness and distributional equity, implications of service provision for trust and legitimacy and the benefits arising from co-production of services. For further information see Donovan (2003). 
concerned with placing the citizen at the core of policymakers' decisions. Not only is citizens' participation crucial in relation to the long-term outcomes of their governance, but it is also an agent for relevant decisions. ${ }^{37}$ Additionally, the issue of citizens' participation is part of a large debate among scholars and thus provides individuals with an opportunity to influence public decisions and has long been a component of the democratic decision-making process. ${ }^{38}$ Simultaneously, the environment for policy and designation has grown in complexity. The ownership of concepts is usually blurred, particularly when more than one department, ministry or levels of government are concerned. ${ }^{39}$

\section{Open Access Practice}

Open access can be defined as the practice of providing online access to scientific content that is free of charge to the reader. In the context of research and development, open access typically focuses on access to scientific information, which refers to two critical categories: a) peer-reviewed scientific research articles (published in academic journals) and b) scientific research data (data underlying publications and/or raw data).

In relation to open access, it is crucial to realise what it actually entails. The practice of open access was initially defined during a meeting in Budapest among a diverse group of open access advocates who were brought together by the Open Society Institute in early December $2001 .{ }^{40}$ In accordance with this definition, open access makes articles freely available on the Internet, permitting any user to read, download, copy, distribute, print, search or link to the full texts of these articles; open access also allows readers to trawl articles for indexing, pass them on as data for software or use them for any other lawful purpose, without financial, legal or technical barriers other than those inseparable from gaining access to the Internet itself. The only constraint on reproduction and distribution, and the only role for copyright in this domain, should be to give authors control over the integrity of their work and the right to be properly acknowledged and cited.

\subsection{Open Access Repositories}

According to Pinfield et al., an OAR is the physical space reserved for permanent or intermediate storage of archival material without any access restrictions. ${ }^{41}$ Yet there are advocates who argue that it is where digital

37. Douglas R Holmes, Integral Europe: Fast-Capitalism, Multiculturalism, Neofascism (Princeton University Press, 2010) ('Integral Europe').

38. Steven Grabow, Mark Hilliker and Joseph Moskal, Comprehensive Planning and Citizen Participation (Extension Service, 2006).

39. Henry E Smith, 'Property Is Not Just a Bundle of Rights' (2011) 8(3) 279.

40. Stefan Baack, 'Datafication and Empowerment: How the Open Data Movement Re-Articulates Notions of Democracy, Participation, and Journalism' (2015) 2(2) Big Data \& Society <https://doi.org/ 10.1177/2053951715594634> ('Datafication and Empowerment').

41. Stephen Pinfield et al, 'Open-Access Repositories Worldwide, 20052012: Past Growth, Current Characteristics, and Future Possibilities' content and assets are stored and can be searched and retrieved for later use. ${ }^{42}$

It is a given fact that the conditions of the modern information environment have evolved through the years, touching on every social aspect of everyday life. ${ }^{43}$ It is also worth mentioning that among every generation of end users, there is a gap in skills with regard to information and communication technologies, obtained through education or lifelong learning. Based on these skills, one is able to fully satisfy information needs within access to any type of information service. Thus, it led to a social division between information-rich (i.e. those with access to information) and information-poor individuals (i.e. those deprived of such access), resulting in informational, and consequently social, inequalities.

By introducing the concept of the Internet and its infrastructure during the 1990s, important change was inflicted on utility and information access opportunities. Moreover, several journals and editions adopted different types of formats. In particular, the traditional print format converted to electronic ones, and journals started publishing their content a few months earlier than the printed edition digitally. As a result, the content of journals became available to registered users by limiting postal delay and annihilating distance by providing home access to information. Thus, it is clear that there is fertile ground for introducing important changes to the information model through an upcoming revolution that could be brought through open access to information via institutional repositories.

\section{Public Policies Relating to OAR}

To determine the proper public policy basis for OAR, it is necessary to examine relevant economic, social and IT policies in the area. It is further necessary to evaluate the merits of these theories, identify inconsistencies between such theories and consider tensions in the applications of such theories.

\subsection{Social Policies in Support of Free Exchange and Access to Information}

According to Diamond's lecture at Hilla University for Humanistic Studies, democracy is a system of government with four key elements: (i) a political system for choosing and replacing the government through free and fair elections, (ii) the active participation of the people, as citizens, in politics and civic life, (iii) the protection of the human rights of all citizens and iv) a rule of

(2014) 65(12) Journal of the Association for Information Science and Technology 2404 ('Open-Access Repositories Worldwide, 2005-2012').

42. Peter Suber, 'Timeline of the Open Access Movement', http:// legacy.earlham.edu/ peters/fos/timeline.htm.

43. Maria Bottis, 'The Protection of Private Life and the European Legislation with Regard to Personal Data: Thoughts on the Protection of Private Life in the USA' in Honorary Volume, Stathopoulos (Sakkoulas, 2009) 809. 
law, in which laws and procedures apply equally to all citizens. ${ }^{44}$ Moreover, it is understood that governments ought to provide services for citizens' equality and protection of human rights.

Nevertheless, it should be mentioned that there is an imminent link between governments and people that manifests in elections. Furthermore, the preceding democratic procedure aims to elect a new government that ought to serve the virtue of democracy by balancing different types of interests. ${ }^{45}$ Therefore, the relationship between government and citizens should be addressed as it illustrates the importance of a proper public policy basis from the social perspective.

According to Fischer (2003), there are five main strategies that should be implemented by governments for fostering incentives for innovation and constructing a 'social cell' in regard to information preservation and distribution. In addition, within these five strategies there are social theories based on the rapid growth of technology for a proper public policy basis in order to balance the interests of copyright owners and end users. Specifically, the five strategies include (i) the social theory of technological innovation, (ii) innovative initiatives theory, (iii) the theory of productive relationship, (iv) the theory of pros or the positive theory and (v) the theory of grants.

Within the social theory of technological innovation, governments can engage in technological innovation themselves. With respect to many sorts of public goods, governments have for centuries responded to the risk of suboptimal private-sector production by supplying the relevant objects or services themselves. Hence, the same theory can be employed in the governmental public policy context of information protection and dissemination. In particular, governmental initiatives should be increased and spread to society.

According to the second theory of innovative initiatives, governments can contribute to innovative initiatives by private actors and thus illustrate that private sector can further support the public good of information conservation and dissemination by implementing the necessary public policy basis for effective governance of OARs.

Third, the theory of productive relationship is based on the idea that there should be a productive relationship between government and citizens. Therefore, prizes and rewards ought to be offered to individuals and organisations who contribute to society by providing beneficial innovations.

Fourth, the theory of pros or the positive theory, in the context of IP law, posits that governments can assist creators (or innovators) by disguising public information that is essential to implement their innovations.

44. Larry Diamond, 'What Is Democracy?' (2004) https://web.stanford. edu/ Idiamond/iraq/WhalsDemocracy012004.htm.

45. Roberto Caso and Federica Giovanella, Balancing Copyright Law in the Digital Age - Comparative Perspectives: Preface (SSRN Scholarly Paper No ID 2529954, Social Science Research Network, 24 November 2014) https://papers.ssrn.com/abstract=2529954 ('Balancing Copyright Law in the Digital Age - Comparative Perspectives').
Thus, incentives are offered to other persons who wish to take advantage of those breakthroughs.

Finally, the theory of grants argues that governments may grant innovators exclusive rights to engage in certain kinds of activities with respect to their innovations. Yet it is illustrated that social justice is of paramount importance for the modern knowledge economy.

\subsection{Economic Theories for Intellectual Property Laws}

The literature shows that the examination of IP has competing interests involved (i.e. those of copyright owners and end users) and could lead someone to investigate their economic impact on the balance among competing IPRs within the legislative framework. ${ }^{46}$ Therefore, economic justifications of IP should be considered as additional means to support the appropriate public policy applied to benefit the governance of OARs. ${ }^{47}$ According to this logic, the economic parameter that stems from IP is of paramount importance. Moreover, economists explore ways of efficiently allocating scarce resources to unlimited wants and realise that private property rights are a plausible way of dealing efficiently with scarcity. ${ }^{48}$ Thus, this issue should be addressed in order to delineate the focal research question of this article.

However, there are advocates who argue that inventions are utilitarian works and that, therefore, the principal economic theory applied is about utilitarianism. ${ }^{49} \mathrm{Kapc}-$ zynski (2012) argues that the field of IP should only use the utilitarian-efficiency approach. Moreover, utilitarian theorists generally endorse the creation of IPRs as an appropriate instrument to foster innovation. ${ }^{50}$ It is argued that the public, authors and inventors have 'signed' a social contract in which the public grants authors and inventors exclusive rights to their works for a limited duration, which provide enough incentive for them to create and develop. ${ }^{51}$ Yet once the exclusivity period expires, the rights are transferred to the public and become part of the public domain. Hence, it is acknowledged that freedom of expression, creation, dissemination of information and its protection ought to coexist in order to support effective outcomes such as innovation. Nevertheless, this justification illustrates the importance of a creator's rights in relation to social evo-

46. Daniele Archibugi and Andrea Filippetti, 'The Globalisation of Intellectual Property Rights: Four Learned Lessons and Four Theses' (2010) 1(2) Global Policy 137 ('The Globalisation of Intellectual Property Rights').

47. Catherine Colston and Kirsty Middleton, Modern Intellectual Property Law (Psychology Press, 2005).

48. Meir Perez Pugatch, The International Political Economy of Intellectual Property Rights (Edward Elgar Publishing, 2004).

49. Frank Arntzenius, 'Utilitarianism, Decision Theory and Eternity' (2014) 28(1) Philosophical Perspectives 31.

50. Peter S. Menell, Intellectual Property and the Property Rights Movement (Social Science Research Network, 12 July 2007) http:// papers.ssrn.com/abstract=1000061.

51. Richard A. Posner, 'Intellectual Property: The Law and Economics Approach' (2005) 19(2) The Journal of Economic Perspectives 57 ('Intellectual Property'); Steven Shavell, Foundations of Economic Analysis of Law (Harvard University Press, 2009). 
lution and the appropriate way that it can be shared while under protection.

In addition, it is undeniable that the majority of authors who pursued economic analyses of IP have relied on the 'Kaldor-Hicks' criterion. The criterion helps lawmakers select a system of regulations that maximises the aggregate welfare, which is measured by the end users' ability and willingness to pay for goods and services in relation to information. ${ }^{52}$ Nevertheless, they disagree sharply about the implications of that criterion in this discipline. Thus, three different economic justifications dominate the literature.

The incentive theory, which is the most common, claims that an optimal doctrine is the one that maximises the difference between (a) the current discounted value to end users of the intellectual products whose creation is induced by holding out to creators and inventors the carrot of monopoly power and (b) the ensemble detriments generated by such a system of incentives. ${ }^{53}$ In other words, this theory urges a governmental lawmaker to establish or grow IP protection. Doing so would help end users by stimulating creativity more than it would hurt them by constricting their access to intellectual products or raising their taxes.

Another one important economic justification is relevant to the patent systems. ${ }^{54}$ Further, its objective is to eliminate or reduce the tendency of IPRs to advance duplicative or uncoordinated inventive activity. ${ }^{55}$ Economic waste of this sort can occur at the three stages in the inventive process.

Finally, it is indispensable to realise that copyright and patent systems play crucial roles in letting potential producers of intellectual products know what end users want. Hence, they channel productive outcomes in directions most likely to enhance the welfare of end users. Based on this rationale, sales and licences will ensure that goods get into the hands of people who need them and who have the ability to pay for them. Only under specific circumstances where transaction costs would prevent such voluntary exchanges should the holders of IPRs be denied total scrutinisation in relation to the use of their works. Therefore, the necessity of a public policy basis is imperative when concerning the governance of OARs.

\subsection{The Relationship between Communication Technologies and Public Policy}

A further dimension to be considered is the interplay between communication technologies and relevant

52. D.N. Dwivedi, Microeconomics: Theory And Applications (Pearson Education India, 2002) ('Microeconomics'); Aristides $N$ Hatzis and Nicholas Mercuro, Law and Economics: Philosophical Issues and Fundamental Questions (Routledge, 2015) ('Law and Economics').

53. Nikos Koutras, Building Equitable Access to Knowledge Through Open Access Repositories (Information Science Reference, 2019).

54. Robert P Merges, Justifying Intellectual Property (Harvard University Press, 2011)

55. Peter S Menell, Mark A Lemley and Robert P Merges, Intellectual Property in the New Technological Age 2017: Vol. Il Copyrights, Trademarks and State IP Protections (Clause 8 Publishing, 2017) ('Intellectual Property in the New Technological Age 2017'). advancements with public policy and its objectives. It is recognised that the discourse about the relationship between communication technologies and public policy ranges across an extensive assortment of concerns. For example, the concern of this article is about the social role of communication scholarship in relation to the analysis and implementation of public policy. As Peterson (2008) claims, the communication is one site where policy is publicly worked over and is the subject of public policy, most notably in laws and regulations on forms of speech, mass media and telecommunication. Therefore, it is admitted that this issue should be examined from a sociological perspective, based on theories relevant to social policy.

It is recognised that communication technologies have created an enormous change in the way that information is generated, regenerated and distributed. Therefore, relevant decisions to adopt appropriate governance frameworks and copyright laws for arising communication technologies and usages of works are complicated. ${ }^{56}$ Thus, it is understood that this issue should be examined as the focal research question of this article is how the public policy basis should be formed to facilitate OARs. Hence, another issue that should be addressed and offer information relevant to this question is the inevitable relationship between communication technologies and public policy.

The significance of communication technologies in conjunction with public policy was depicted within the twenty first meeting of the International Colloquium on Communication in 2008, which focused on communication and public policy. ${ }^{57}$ Moreover, it is undeniable that information is of paramount importance in relation to communication technologies. As Drahos) states, the term of information is the most significant primary good. Yet he insists that this stems from its role in the economy, the development of knowledge and culture and its impact on power in a society. ${ }^{58}$ This is beneficial in order to understand the crucial role of information regarding the needs relevant to communication.

Other scholars also claim that the importance of information as primary good can be valued beneficially by concentrating on the outcomes of its imperfect deficient dispersion. ${ }^{59}$ Prejudgements of various kinds are paradigms of deficient dispersion. However, it is not acceptable to embrace these negative aspects as far as the concept of communication technologies and its contexts are examined in relation to public policy modern regimes. To sum up, it is understood that public policy is another

56. Sophia Christou and Alana Maurushat, 'Waltzing Matilda' or 'Advance Australia Fair'? User-Generated Content and Fair Dealing in Australian Copyright Law (SSRN Scholarly Paper No ID 1457570, Social Science Research Network, 17 August 2009) <http://papers.ssrn.com/ abstract $=1457570>$ ("WWaltzing Matilda" or "Advance Australia Fair"?').

57. Eric Peterson, 'An Introduction to Communication and Public Policy' (2009) 1.

58. P. Drahos, Regulatory Theory: Foundations and Applications (ANU Press, 2017) ('Regulatory Theory').

59. Rochelle Cooper Dreyfuss and Justine Pila, The Oxford Handbook of Intellectual Property Law (Oxford University Press, 2018). 
concept that can outperform the rapid development of communication technologies. Therefore, it should be adopted to these evolved norms and frameworks rather than being effective and more responsive to the needs of citizens at the national and international levels.

\section{Discussion}

The previous discussion illustrates that there is a need to propose a socio-economic framework. The proposed framework aims to reconcile and integrate the appropriate social and economic policy discussed earlier. This helps us consider tensions and current options for weighing and reconciling such tensions. In this respect, combining one social theory with one economic theory has the potential to build a scientific approach or strategy to counterbalance competing interests.

Owing to the social theory of technological innovation, governments can engage in technological innovation themselves. In other words, governments ought to take additional initiatives to boost and support individuals' creativity and innovation. As the literature reflects, governments should consider the role of the private sector in the context of public goods production. ${ }^{60}$ Therefore, governments should play a more central role in terms of initiatives that increase innovation. This social theory sets up a societal finality on behalf of governments' role and its contribution to society. Hence, this theory should be complementary to the applied public policy in the context of initiatives to support intellectual protection and further information dissemination.

Given this, the incentive theory demonstrates the economic theory that should be the second complementary element of the proposed socio-economic framework. Accordingly, it is maintained that governmental lawmakers should pursue increased IP protection while stimulating individuals' creativity, which in turn helps further innovation. It is also argued that inventions do not generally implicate the personal interests of the creator. ${ }^{61}$

The proposed framework could be called the 'Techinncentive' framework. This framework would set up the appropriate basis for providing incentives for technological innovation. Additionally, it has the potential to be applied in the context of public policy on behalf of government: (a) to further support IP protection, (b) to increase individuals' involvement (for example actors from private sector) in the production of innovations with societal benefits, (c) to facilitate access opportunities to scientific information produced by educational institutes (i.e. universities, colleges, senior schools, research centres) and (d) to boost dissemination of information via green open access. All in all, the objectives of 'Techinncentive' has the potential to benefit also the academic society towards the production of knowledge and distribution of scientific research results.

60. Lionel Orchard and Hugh Stretton, Public Goods, Public Enterprise, Public Choice: Theoretical Foundations of the Contemporary Attack on Government (Springer, 2016) ('Public Goods, Public Enterprise, Public (hoice').

61. Akash Kamal Mishra, Intellectual Property Rights In Cyberspace (Cyberlekh Publications, 2019). 